\title{
Effectiveness of planned teaching programme, on risk factors of coronary artery disease (CAD) to create knowledge and preventive health behaviour among administrative employees
}

\author{
Rajesh Kumar Sharma \\ Lecturer, Himalayan College of Nursing, HIHT, Dehradun, India
}

\begin{abstract}
:
Aim: The main aim of the study was to evaluate the effectiveness of a planned teaching programme regarding the knowledge of risk factors of CAD among the administrative employees of selected colleges

Material and methods: in selected colleges administrative employees were selected through simple random technique 60 administrative employees were selected, 30 each in experimental group and control group. Data were collected by (1) structured knowledge questionnaire on CAD (2) Structured self rating scale on CAD. Content validation and reliability was established for all tools. On $1^{\text {st }}$ day after random selection of subjects, pre-tests were administrated to both, i.e., the experimental and control groups. Next day the PTP on risk factors of CAD was conducted to the experimental group. On $8^{\text {th }}$ day of PTP post-test was given to both the groups using the same tools.

Analysis: Most of the sample (experimental group-80\%, control group-86.7\%) had moderate knowledge regarding risk factors of CAD in the pre-test. Whereas the mean percentage post-test scores and the modified gain scores in all areas were found to be high in experimental group only. There was significant difference between pre-test post-test knowledge scores in experimental group only $\left(t_{29}=13.717, p<0.05\right)$. The effectiveness of planned teaching programme between experimental group and control group $\left(t_{58}=12.179, p<0.05\right)$ was highly significant. There was no significant association between pre-test knowledge and selected demographic variables.
\end{abstract}

Conclusion: It was concluded that the planned teaching program is an effective strategy which can help administrative employees to increase their knowledge and preventive health behaviour regarding risk factors of $C A D$.

Key words: Effectiveness Planned teaching programme, Risk factor, Coronary artery disease (CAD), Knowledge and Administrative Employees.

\section{Introduction}

The incidence of cardiovascular diseases (CVD) is on the rise in modern world. Coronary Artery Disease (CAD) is a leading cause of cardio vascular mortality worldwide with $>4.5$ million deaths occurring in developing world ${ }^{1}$.

Due to industrialization and changing feature of socio-economic scenario, the incidence of CAD is rising in developing countries as well ${ }^{2}$. Cardiovascular deaths in India are estimated to be 2.5 million per year. Prevalence of coronary artery disease in India is three to four folds higher than in America and Europe . $^{3}$

It has been believed that public awareness programme \& community education is the best instrument to create the knowledge and in the prevention of occurrence of CAD by helping people to take care of their own health.

\section{Need for the study}

Indians have the highest rates of CAD all over the world. It is 2 to 4 time higher at all ages and 5 to 10 time higher in those below 40 years of age. The excess burden of CAD in Indians is due to combination of nature (Genetic predisposition) and decreased physical activity and increased consumption of calories and metabolic abnormalities appears to have a synergistic effect on the development of CAD in genetically predisposed individuals ${ }^{4}$.

CAD epidemics are essentially preventable according to existing knowledge. In the majority of developed countries CAD mortality has fallen by a third or half in the last two decades. In USA the SMR (Standard mortality rate) of CAD is decline by $54 \%$. The rate of decline in CAD was substantially greater among educated. This is a clear proof that the ravages of CAD can be reduced mainly by modifying the lifestyle ${ }^{5}$.

Several studies have found that the knowledge about the risk factors of CHD of the population under study was inadequate. Further the clinical experience of the researcher also shows that in general, people have 
the lack knowledge about the risk factors of CAD. It is the adult group, which suffers more from CHD, just because of their unhealthy life styles. Knowledge, awareness of risk status, scenario of disease and planned teaching programme about the risk factors of CAD can motivate people to take preventive measures. It is obvious that the need for community awareness is very high and no longer can be delayed

\section{Problem}

A study to evaluate the effectiveness of planned teaching programme on risk factors of coronary artery disease (CAD) to create knowledge among administrative employees in selected colleges of Dakshina Kannada district of India.

\section{Objectives}

1. Assess the knowledge regarding risk factors of $\mathrm{CAD}$ among administrative employees

2. Find the effectiveness of planned teaching programme between pre-test $\&$ post-test knowledge regarding risk factors of CAD.

3. Compare the effectiveness of planned teaching programme between the experimental and control group on knowledge of risk factors of CAD.

4. Find the association of pre-test level of knowledge with the demographic

\section{Methodology}

A Quantitative evaluative research approach was used for the study. The research design adopted was pre-test post-test control group design. Data collected by simple random technique. The sample consist 60 administrative employees (30 experimental and 30 control groups).

The tools developed and selected for the data collection were: (1). Structured knowledge questionnaire on CAD, to assess the knowledge about risk factors of CAD, (2). Structured self rating scale on CAD to assess preventive health behaviour. Content validation and reliability was established for all tools. Final data collection was done from all the selected colleges of Dakshina Kannada district. After obtaining consent \& permission from the respondents, pre-test was conducted; pre-test was completed in 6 days. Planned teaching programme with regards to risk factors of CAD was administered on the 2nd day to the experimental group only. It was given in 4 groups, having different numbers of subjects in each group. The method of instruction adopted was lecture cum discussion. After the teaching session, the subjects were asked to clarify their doubts. After a week of teaching the post-test was administered on both groups.

\section{Result}

Section I: Distribution of participants on selected demographic characteristics

The data in experimental group the maximum number (i.e. 53.3\%) of participants were in the age group of 20-30 years, whereas in control group maximum number (50\%) were in age group of 31-40 years. Regarding the gender, in experimental group, the majority of participants (63.3\%) were female but in control group majority of participants $(56.7 \%)$ were male. With regards to marital status in both groups most of participants (experimental group-53.3\%, control group-73.3\%) were married. The table further shows that with respect to religion, in both the groups maximum number of participants (experimental group-80\%, control group-73.3\%) were Hindu and few Muslims. Regarding food habit nearly half of participants in both group were vegetarian and remains non-vegetarian in both groups. With regards to education most of the participants (experimental group-73.3\%, control group-60\%) were graduate. Regarding the sitting hours in office without physical mobility, most of the participants (experimental group- $46 \%$, control group-53.3\%) were sitting in office for 3 to 4 hours per day. Regarding the source of getting health related information, most of the participants (60\%) in experimental group getting from mass media, whereas most of participants (50\%) in control group getting from literature. Regarding watching health related programme on TV most of participants (43.3\%) in experimental group watching TV rarely and in control group majority of participants $(53.3 \%)$ were watching occasionally. Regarding the attending talk/seminars on heart diseases in experimental group only 5\% participants attended the seminar and in control group none had attended it.

Section II: Evaluation of planned teaching programme in terms of gain in knowledge scores

Table 1: Frequency and percentage distribution of pre-test knowledge scores of subjects

\begin{tabular}{|l|l|l|l|l|}
\hline \multirow{2}{*}{$\begin{array}{l}\text { Level of } \\
\text { knowledge }\end{array}$} & \multicolumn{2}{|l|}{ Experimental group } & \multicolumn{2}{l|}{ Control group } \\
\cline { 2 - 5 } & Frequency & $\%$ & Frequency & $\%$ \\
\hline Low & 3 & 10.0 & 2 & 6.7 \\
\hline Moderate & 24 & 80.0 & 26 & 86.7 \\
\hline High & 3 & 10.0 & 2 & 6.7 \\
\hline
\end{tabular}


The data presented in the Table 1 shows that majority of the subjects in both in the experimental group $(80.0 \%)$ and the control group $(86.7 \%)$ had moderate knowledge regarding risk factors of CAD.

Table 2: Frequency and percentage distribution of post-test knowledge scores of subjects $\mathbf{N}=\mathbf{6 0}$

\begin{tabular}{|l|l|l|l|l|}
\hline \multirow{2}{*}{$\begin{array}{l}\text { Level } \\
\text { knowledge }\end{array}$} & Experimental group & \multicolumn{2}{l|}{ Control group } \\
\cline { 2 - 5 } & Frequency & $\%$ & Frequency & $\%$ \\
\hline Low & - & - & 2 & 6.7 \\
\hline Moderate & 4 & 13.3 & 24 & 80.0 \\
\hline High & 26 & 86.7 & 4 & 13.3 \\
\hline
\end{tabular}

The presented data in Table 2 shows that in experimental group after administration of the planned teaching programme majority of participants have high level of knowledge whereas in control group (without planned teaching programme) majority of participants (80\%) have moderate level of knowledge.

Table 3: Frequency and percentage distribution of preventive health behaviour self rating scales score of subjects

$\mathbf{N}=\mathbf{6 0}$

\begin{tabular}{|l|l|l|l|l|l|l|}
\hline \multirow{2}{*}{$\begin{array}{l}\text { Score of self } \\
\text { rating scale }\end{array}$} & \multicolumn{2}{|l|}{ Experimental group } & \multicolumn{2}{l|}{ Control group } & \multicolumn{2}{l|}{ Total } \\
\cline { 2 - 7 } & $\mathbf{f}$ & $\mathbf{\%}$ & $\mathbf{f}$ & $\mathbf{\%}$ & $\mathbf{f}$ & $\mathbf{\%}$ \\
\hline Low & 8 & 26.7 & 4 & 13.3 & 12 & 20.0 \\
\hline Moderate & 9 & 30.0 & 8 & 26.7 & 17 & 28.3 \\
\hline High & 13 & 43.3 & 18 & 60.0 & 31 & 51.7 \\
\hline
\end{tabular}

The data presented in Table 3 shows that in both groups highest percentage of participants (experimental group-43.3\%, control group-60\%) had high preventive health behaviour self rating scale scores.

Table 4: Mean, median and standard deviation of pre-test and post-test knowledge score of experimental and control group

\begin{tabular}{|l|l|l|l|l|l|l|}
\multicolumn{9}{|c|}{ N $=60$} \\
\hline \multirow{2}{*}{ Knowledge score } & \multicolumn{2}{|l|}{ Mean } & Median & \multicolumn{2}{l|}{ SD } \\
\cline { 2 - 7 } & Exp. & Control & Exp. & Control & Exp. & Control \\
\hline Pre test & 28.5 & 28.80 & 29 & 29 & 4.09 & 3.53 \\
\hline Post-test & 35.9 & 29.17 & 36 & 28 & 2.42 & 3.48 \\
\hline
\end{tabular}

The data presented in Table 4 shows that in experimental group the post-test mean knowledge score was higher than the mean pre-test knowledge score, (experimental group - pre-test-28.50, post-test-35.90) whereas in control group there is very slight difference between post-test and pre-test knowledge score. In experimental group post-test median was higher than the pre-test score (experimental group - pre-test-29 and post-test-36) whereas in control group the pre-test median was slight higher than post-test median. This showed there was a knowledge gain in experimental group post after the planned teaching programme. The score of experimental group (experimental group - pre-test SD-4.092, post-test SD-2.429) seemed to be more dispersed then the post-test, whereas in control group there was no gain in knowledge.

Section III: Test to find out the difference between the means of pre-test and post-test knowledge score A paired ' $t$ ' test was computed in order to find out the significance of difference between the means of pre-test and post-test knowledge as given below-

Area wise significance of difference

Table 5: Mean, mean difference and ' $t$ ' value of pre-test and post-test knowledge score $N=60$

\begin{tabular}{|c|c|c|c|c|c|c|c|c|}
\hline \multirow{3}{*}{ Area } & \multicolumn{4}{|c|}{ Mean knowledge score } & \multirow{2}{*}{\multicolumn{2}{|c|}{ Mean difference }} & \multirow{2}{*}{\multicolumn{2}{|c|}{ 't' value }} \\
\hline & \multicolumn{2}{|c|}{ Pre-test } & \multicolumn{2}{|l|}{ Post-test } & & & & \\
\hline & Exp group & Control group & Exp group & Control group & Exp group & Control group & Exp group & Control group \\
\hline Area 1 & 4.43 & 4.63 & 6.07 & 4.73 & 1.64 & 0.10 & 7.527 & 1.114 \\
\hline Area 2 & 2.37 & 2.00 & 2.73 & 2.10 & 0.36 & 0.10 & 3.003 & 1.796 \\
\hline Area 3 & 22.03 & 22.27 & 27.10 & 22.30 & 5.07 & 0.03 & 10.467 & 1.114 \\
\hline Total & 28.50 & 28.80 & 35.90 & 29.17 & 7.40 & 0.37 & 13.717 & 1.114 \\
\hline
\end{tabular}

$\mathrm{t}_{29}=2.01, \mathrm{P}<0.05$ 
Key:

Area 1: Anatomy and physiology of heart

Area 2: Non-modifiable risk factors of coronary arterial disease

Area 3: Modifiable risk factors of coronary arterial disease

The mean post-test scores of experimental group was higher in the all areas of risk factors of CAD than their pre-test knowledge scores. ' $t$ ' values computed in all areas were significant at 0.05 level. This showed that in experimental group, there was a significant gain in the knowledge scores in all areas of CAD. Therefore the planned teaching programme was an effective method of increasing the participant's knowledge on risk factors of CAD.

\section{Section IV: Finding out the effectiveness between the experimental and control group}

An unpaired ' $t$ ' test was computed in order to find out the effectiveness between the experimental and control group.

Table 6: Mean difference, SD of difference and ' $t$ ' value of experimental and control group

$$
\mathbf{N}=\mathbf{6 0}
$$

\begin{tabular}{|l|l|l|l|}
\hline Group & $\begin{array}{l}\text { Mean of } \\
\text { difference }\end{array}$ & $\begin{array}{l}\text { Standard deviation } \\
\text { of difference }\end{array}$ & t value \\
\hline Experimental group & 7.4000 & 2.954 & 12.179 \\
\hline Control group & 0.3667 & 1.129 & \\
\hline
\end{tabular}

Data Presented in table-6 shows that there is high mean difference between the experimental group and control group. To find out the effectiveness in value, ' $t$ ' test was computed and obtained value $\left(t_{58}=12.179\right.$, $\mathrm{p}<0.05$ ) was found to be highly significant.

\section{Section V: Association between pre-test level of knowledge score and the demographic variables}

To find out the relationship between the pre-test knowledge scores and the demographic variables Chisquare test was computed.

The computed chi-square value for demographic variables, viz., age, sex, marital status, religion, food habits, educational qualification, sitting in office without physical mobility, getting health related information, watching health related programme on TV and attending seminar on heart disease, were less than table value under respective degrees of freedom. There is no significant association between these demographic variables and the pre test level of knowledge, which suggests that the knowledge was independent of the risk factors.

\section{Discussion}

The findings of the study had been discussed with reference to the objectives and hypothesis stated in Chapter I and in relation with the findings of other studies.

\section{Finding related to Demographic data}

The findings of the study demonstrated that Majority of the samples in experimental group were in the age group of 20-30 years (53.3\%) and those in the control group were in age group of 31-40 years (50\%). In experimental group (63.3\%) were female, control group (56.7\%) were male. Experimental group - 53.3\%, control group- $73.3 \%$ were married. Experimental group - 80\%, control group- $73.3 \%$ were Hindu. Nearly half of participants in both groups were vegetarian and remains non-vegetarian. Experimental group - 73.3\%, control group-60\% were graduates. Experimental group - $46 \%$, control group- $53.3 \%$ were sitting in the office for 3 to 4 hours per day. Experimental group (60\%) getting from mass media, control group (50\%) getting health related information from literature. Experimental group (43.3\%) watching TV rarely, control group (53.3\%) majority of participants $(53.3 \%)$ were watching occasionally. Experimental group only $5 \%$ attended the seminars on heart disease, control group none of has attended it.

\section{Knowledge of administrative employees regarding risk factors of CAD}

Findings of the study show that in the experimental group majority of participants $(80 \%)$ were in moderate level of knowledge, whereas in control group majority (86.7) also were in moderate level of knowledge. These finding were consistent with the findings of Juliet (2005), on the population of college teachers with regards to knowledge on risk factors of hypertension, found that teachers had moderate level of knowledge about the risk factors of hypertension ${ }^{6}$. 


\section{Comparison between pre-test and post-test knowledge scores}

The findings of the study revealed that the pre-test mean percentage knowledge scores regarding knowledge of risk factors of CAD were found to be less than post-test mean percentage knowledge scores, whereas there was no significant difference between pre-test mean and post-test mean knowledge scores of control group.

\section{Effectiveness of PTP between experimental and control group}

The findings of the present study revealed that there is high mean difference between the experimental group (7.4) and control group (0.37) were found highly significant $\left(\mathrm{t}_{58}=12.179, \mathrm{p}<0.05\right)$.

The findings showed that planned teaching programme was effective in improving the participant's knowledge ${ }^{7}$.

\section{Association of pre-test knowledge with selected demographic variables}

The findings of the study showed that there was no significant association between pre-test knowledge level and the demographic variables.

\section{Recommendations/future scope}

On the basis of the findings of the study, it is recommended that:

- A study can be replicated on a larger sample thereby findings can be generalized for a larger population.

- A longitudinal study may be conducted to determine the effect of planned teaching programme on the knowledge, risk status and on the preventive health behaviour of the normal adults.

- A similar study can be conducted in different settings i.e. communities, industries, hospitals, schools and other institutions.

- A similar study can be done using other teaching strategies i.e. Self-instructional Modules etc.

- A study may be conducted to assess the association between the risk status for CAD and preventive health behaviour for $\mathrm{CAD}$ of normal adults.

\section{Conclusion}

It was concluded that the planned teaching and other awareness programme will improve the knowledge of the administrative employees. In this present study enlightened in the investigator the most of the risk factors of modifiable. The PTP is affective in meaningful learning. If the public is properly educated they can act as resource personal to impart knowledge and modify the preventive health behaviour of their family and thus to the community.

\section{References}

[1]. Murray CJ, Lopez AD. The global burden of disease: A Comprehensive assessment of mortality and disability from disease, injuries and risk factors in 2000 and projected to $2020 \mathrm{~J}$ Health Risk Manag 2000.

[2]. Yavagal ST. Prevention is better than cure. [Online]. Available from: URL:http://www.pubmed.com.

[3]. Gupta R, Gupta VP. Meta analysis of coronary heart disease prevalence in India. Indian Heart Journal 2001 Jan;48:241-5.

[4]. Enas A. Coronary artery disease epidemic in Indians: a cause for alarm and call for action. J Indian Med Assoc 2000 Dec; 98(11):694-702.

[5]. Goldman L, Cook EF. The decline in ischemic heart disease mortality rates: an analysis of the comparative effects of medical interventions and changes in lifestyle. Ann Intern Med 1996;(101):825-36.

[6]. Juliet RM. The study of risk status and effectiveness of two planned awareness programmes on the prevention of hypertension of college faculty members of Mangalore University, Mangalore. Unpublished master of philosophy thesis submitted to MAHE, Manipal; 2001.

[7]. Francis J. A study to evaluate the effectiveness of planned teaching programme on the knowledge of school teachers regarding risk factors of CHD. Unpublished masters of nursing thesis submitted to Mangalore University.

\section{Author's Profile}

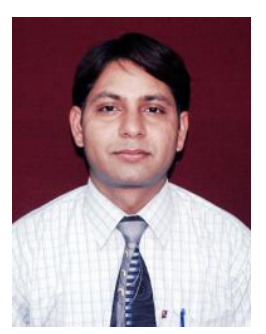

Mr. Rajesh Kumar Sharma, Working as a Lecturer/Assistant Professor in Himalayan College of Nursing, HIHT, Dehradun, India. He has completed his graduation in 2002 \& Masters in Nursing from Rajeev Gandhi University of Health sciences in 2008. He is having 8 year teaching experience and Guided more than 10 Post graduate \& Under-graduate Research Projects. He has presented research articles in National conferences. He has also organized, attended \& been as resource person in various state, national \& International Workshops \& Seminars. He is also Perusing PGDipHPE from KLE University of India with an International collaboration with UIC, Chicago, USA. 